- 研究简报・

\title{
云南白尾梢虹雉的分布与保护
}

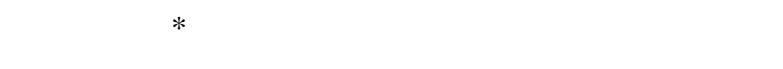

(西南林学院保护生物学学院, 昆明 650224)

\begin{abstract}
摘要 : 1999-2003 年在云南对白尾梢虹雉 (Lophophorus sclateri)的分布及栖息生境进行了调查, 确证 11 个分布点, 另有 3 个点可能有分布。白尾梢虹雉在云南的栖息生境主要有高山草甸、高山亚高山箭竹林及亚高山针叶林 3 种 类型。栖息生境承载量小、种群增长慢、人类活动干扰以及宣传不力是白尾梢虹雉濒危的主要因素, 据此提出开展 驯养繁殖、加强禁止偷猎的法制宣传，以及加强基础研究的保护建议。
\end{abstract}

关键词 : 白尾梢虹雉 ,分布现状 栖息地 致危因素

中图分类号 : Q958 文献标识码 :A 文章编号 : 1005-0094(2004)05-0523-05

\section{The distribution and conservation of Sclater's monal in Yunnan, China}

\author{
HAN Lian-Xian* , HUANG Shi-Lin , LUO Xu , YANG Hong-Jun \\ Biology Conservation Faculty , Southwest Forestry College , Kunming 650224
}

\begin{abstract}
Sclater's monal (Lophophorus sclateri) is an endangered species in the Galliformes, with restricted distribution in Tibet and Yunnan. In Yunnan, the bird formerly has only been recorded at three sites. A survey on the distribution and habitat of this species was undertaken from October 1999 to August 2003 , resulting in confirmation of the present occurrence of the species in eleven localities in seven counties in Yunnan, together with an additional possible three localities to be further confirmed. Sclater's monals were most frequently observed in three types of habitats : alpine meadow, alpine-subalpine bamboo , and subalpine coniferous forestry. Threats to the survival of this pheasant arise from the low carrying capacity of the habitat, low growth rate of the population, human disturbance, and low public awareness. Based on this study, we recommend pilot programmes of captive breeding, regulation of poaching , and encouragement of basic biological research for effective protection.
\end{abstract}

Key words : Lophophorus sclateri, distribution status, habitat, limited factors

白尾梢虹雉 (Lophophorus sclateri) 隶属鸡形目雉 科虹雉属, 在我国主要分布于西藏和云南。在西藏 见于东南部米林县西南的 $\mathrm{Lo} \mathrm{La}\left(\right.$ 约 $28^{\circ} 50^{\prime} \mathrm{N} 、 94^{\circ} 00^{\prime}$ E)、易贡藏布下游地区、丹巴曲上游山脉和伯舒拉 岭等地。在云南沿怒江两岸的怒山山脉 (原碧罗雪 山) 和高黎贡山山脉分布。中国境外分布局限于缅 甸东北山地和印度东北部( 何芬奇 ,1991)。

白尾梢虹雉因数量稀少, 分布范围狭窄, 被列入 国际濒危物种贸易公约附录 I (Appendix I of the Convention on International Trade in Endangered Species of Wild Fauna and Flora) 中,IUCN 濒危物种红 皮书 1994 年和 2000 年均将其列为易危种 ( Fuller \& Garson 2000)。中国野生动物保护法将其列为国家
I 级重点保护种类。何芬奇 (1991)、施晓春 (1999) 在云南西部曾做过白尾梢虹雉的生态学研究。作者 于 1999 年 10 月至 2003 年 8 月在滇西对白尾梢虹 雉的分布、栖息地类型和保护现状进行了调查 现将 结果报道如下。

\section{1 调查时间、地点和方法}

野外调查工作分别在 1999 年 10 月 16 日至 29 日、2000年 8 月 5 日至 8 月 20 日、2001 年 3 月 12 日至 4 月 15 日、2001 年 4 月 19 日至 5 月 5 日、2002 年 3 月 25 日至 4 月 9 日、2003 年 5 月 3 日至 12 日、 2003 年 8 月 17 日至 25 日进行。调查区域包括云南 贡山、福贡、沪水、兰坪、云龙、腾冲、保山、德钦、维西 
9 县。

调查采用先访问当地保护区工作人员以及有狩 猎经历的群众, 出示雉类彩图让他们辨认，了解当地 雉类的种类与分布，若受访者反映本地有白尾梢虹 雉, 则进行实地观察, 最后以实际观察结果作为该地 有白尾梢虹雉分布的依据，进而观察收集栖息地生 境资料。

\section{2 调查结果}

\section{1 分布}

唐蟾珠 (1996)、杨晓君 (1995) 记载以下白尾梢 虹雉采集点 :腾冲大塘、贡山东哨房、贡山巴坡三队、
贡山西哨房及碧江碧罗雪山。本次调查仍在这些采 集点发现有白尾梢虹雉活动。因贡山东哨房和西哨 房位于高黎贡山山脊两侧，两点之间以及与较低海 拔的巴坡三队均相距不远，故文中将此 3 个采集点 合为 1 个分布点 贡山县 12 号桥”。本次调查记录 到 8 个白尾梢虹雉新的分布点, 另有 3 个点通过访 问获悉可能有白尾梢虹雉分布，但未实地考察，需进 一步调查证实。白尾梢虹雉在云南的分布资料详见 表 1 和图 1 。

本调查表明白尾梢虹雉在云南的地理分布为 $25^{\circ} 17^{\prime}-28^{\circ} 05^{\prime} \mathrm{N}, 98^{\circ} 08^{\prime}-99^{\circ} 02^{\prime} \mathrm{E}$, 沿山脉呈狭长 分布。在碧罗雪山的调查结果与何芬奇 (1991)“碧

表 1 云南白尾梢虹雉分布情况调查表

Table 1 Distribution data on Sclater's monal (Lophophorus sclateri) in Yunnan

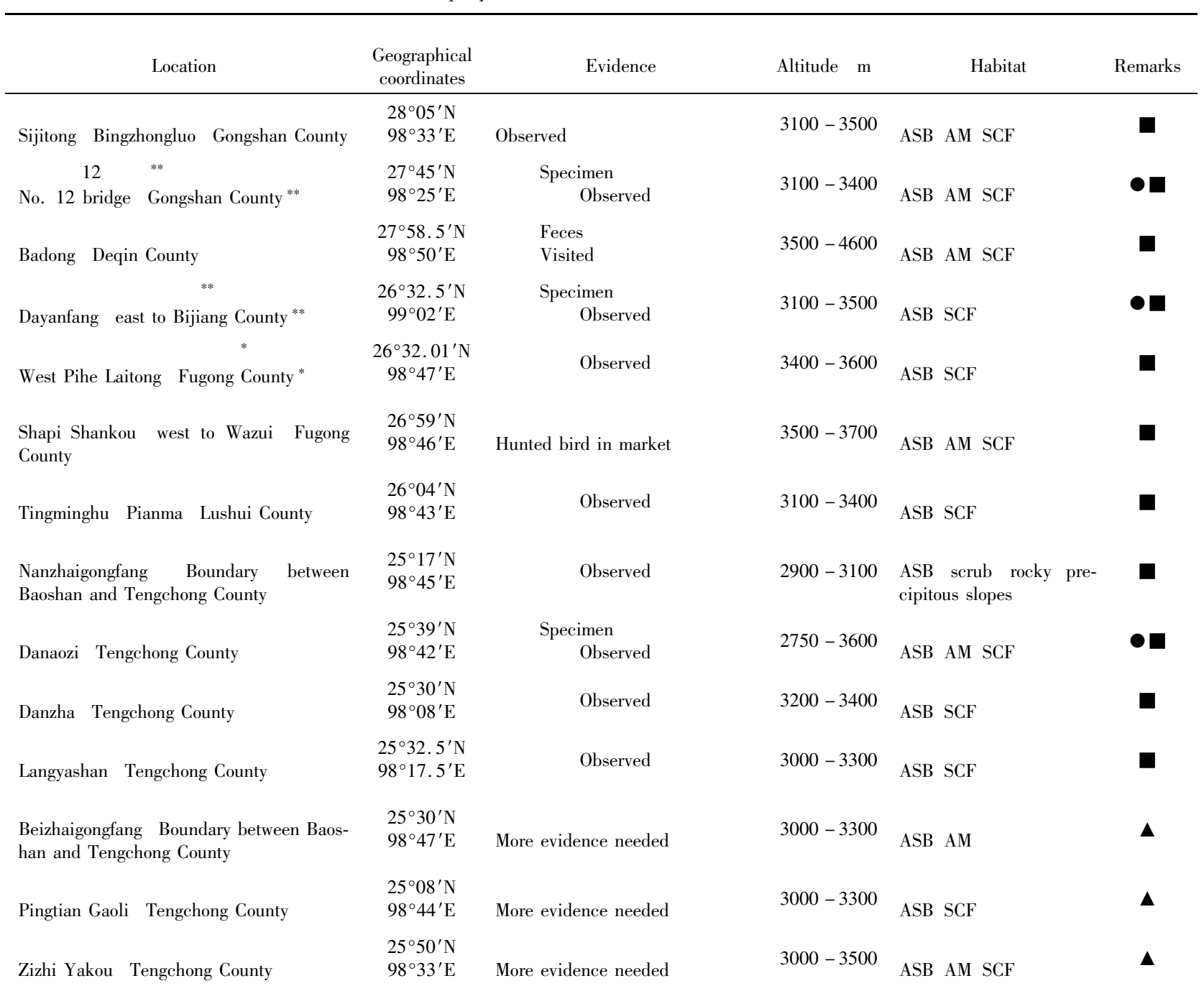




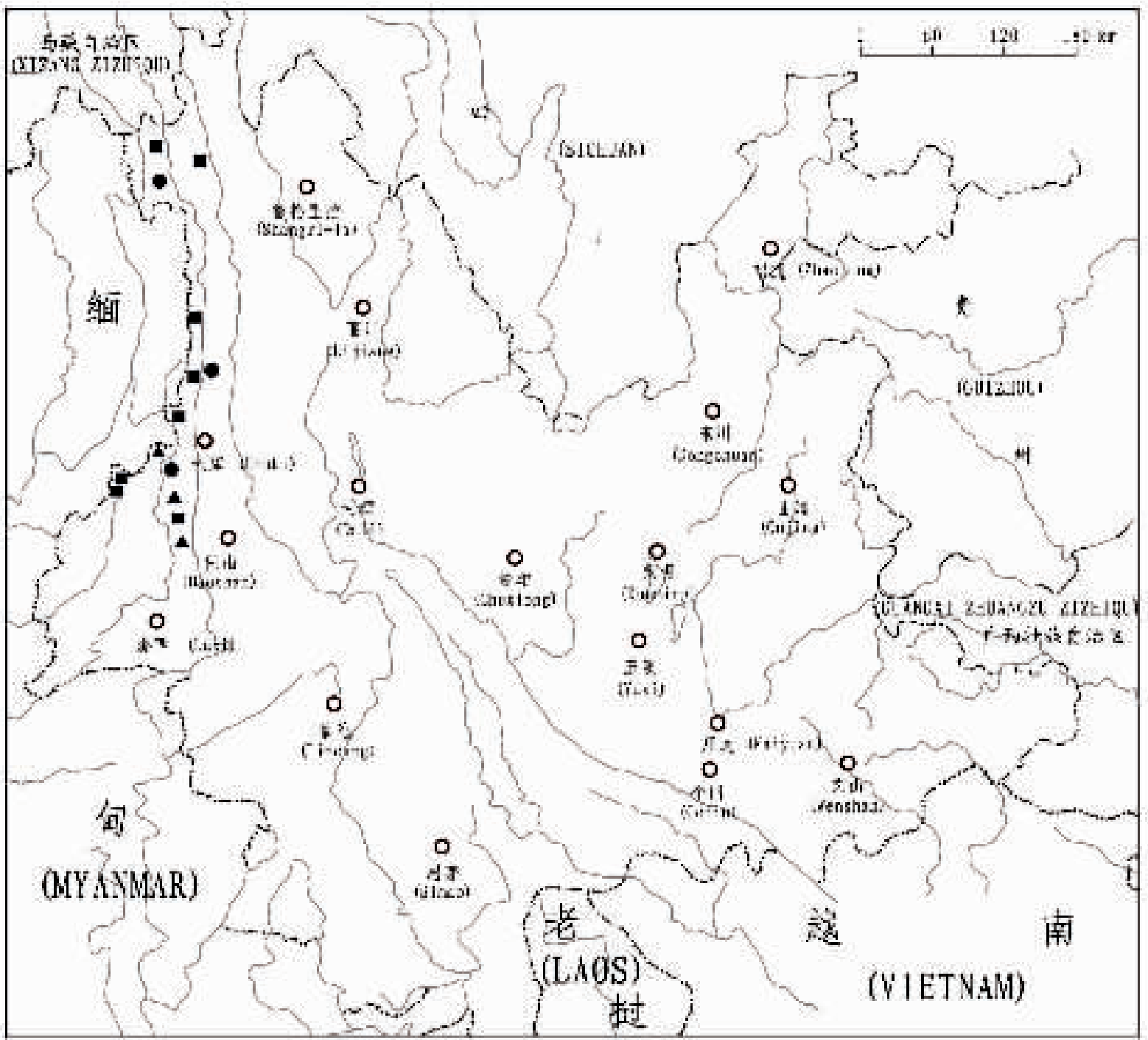

图 1 云南白尾梢虹雉分布图 (符号代表含义同表 1)

Fig. 1 The range of Sclater's monal (Lophophorus sclateri) in Yunnan (Symbols as in Table 1)

罗雪山为白尾梢虹雉在横断山脉中段分布的东界， 在碧罗雪山的分布最南端止于碧江，约 $26^{\circ} 30^{\prime} \mathrm{N}$, $99^{\circ} 00^{\prime} \mathrm{E} "$ 的结论一致。在高黎贡山的调查结果表明 白尾梢虹雉向南延伸已超过原有记录一一腾冲大塘 和西北部的尖高山 ( 郑作新, 1978; 中国科学院昆明 动物研究所鸟类组, 1980), 直至腾冲与保山交界处 的南斋公房 $\left(25^{\circ} 17^{\prime} \mathrm{N}\right)$ 。根据高黎贡山主山脊生境 和地形的相似性，以及作者在腾冲大塘对白尾梢虹 雉春、冬季垂直迁移的研究, 推测白尾梢虹雉在高黎 贡山的分布最南端可能到达腾冲上云乡平田高黎一 带 $\left(25^{\circ} 08^{\prime} \mathrm{N}, 98^{\circ} 44^{\prime} \mathrm{E}\right)$ 。

\section{2 栖息生境}

依据目前收集到的资料，白尾梢虹雉在云南的 栖息生境主要有以下 3 种类型。

\section{2 .1 高山草甸}

高山草甸大多位于山脊附近, 随纬度变化而出 现于不同海拔带, 在南斋公房可低至海拔 $3000 \mathrm{~m}$, 而在德钦巴东则分布在海拔 $4000 \mathrm{~m}$ 以上, 常与箭竹 林或灌丛相间分布或呈大面积开阔型草地。草本种 类繁多，为白尾梢虹雉提供多种食物，在腾冲大脑子 多次见到白尾梢虹雉在该类型生境中受食。草本优 势种类如嵩草 (Kobresia sp. )、多星非 ( Allium walli- 
chii) 、匍匐葈本 (Ligusticum reptans)、香白芷 (Heracleum barmanicum)、展苞灯心草 (Juncus thomsonii)、 尼泊尔绿线蓠 (Meconopsis napalensis)、粗茎贝母 (Fritillaria crassicaulis) 、大萼党参 (Codonopsis macrocalyx) 等。

\subsection{2 高山亚高山箭竹林}

高山亚高山箭竹林多呈大面积的单优群落出现 或作为针叶林下较为密集的下层植被。白尾梢虹雉 主要栖息于矩鞘箭竹 (Fargesia orbiculata) 林和云龙 箭竹 ( $F$. papyifera ) 林中。在四季桶村、片马、南斋 公房、大脑子等地点均见白尾梢虹雉于该种生境中 活动, 是白尾梢虹雉的最主要栖息场所。

矩鞘箭竹是滇西北地区分布海拔最高的竹种， 多分布于 $3100-3700 \mathrm{~m}$ 树线或树线以上, 常在山脊 或近山脊地带呈十分密集的大面积单优群落。间分 布有稀疏的苍山冷杉(Abies delavayi)。竹林中混生 少量茶蔍子 (Ribes spp.)、山石榴 (Rosa omeiensis)、 凸尖杜鹃 (Rhododendron sinogrande) 等灌木。草本 种类相对较多, 主要种类有美丽龙胆 (Gentiana formosa)、三叶悬钩子 (Rubus delavayi)、鞭打绣球 ( Hemiphragma heterophyllum) 、鹿蹄草 (Pyrola decorata) 、头花蓼 (Polygonum capitatum) 及乌头 (Aconitum spp. )、报春 (Primula spp. ) 等。

云龙箭竹集中分布于海拔 $2800-3600 \mathrm{~m}$ 处, 仅 低于矩鞘箭竹。林下混生少量高山蓄薇 (Rosa transmorrisonensis)、西南绣球 (Hydrangea davidii)、长 苞十大功劳 (Mahonia longibracteata)、黄泡 ( Rubus obcordatus) 及木姜子 ( Litsea pungens) 等灌木。草本 植物有委陵菜 (Potentilla sp. )、毛蕨 (Pteridum aquiilinum)、大籽獐牙菜 (Swertia macrosperm)、四回毛枝 䒴 (Leptorumohra quadipinnata)、金茅 (Eulalia speciosa) 及芒萁 (Dicranoteris dichotoma) 等。

\subsection{3 亚高山针叶林}

优势种主要为云南铁杉 (Tsuga dumosa) 和垂枝 香柏 (Sabina pingii) ，多呈小块状分布，常混生苍山 冷杉、槭树 (Acer sp.) 、红桦 (Betula albo-sinensis)、花 楸( Sorbus sp.) 等。森林郁闭度大，林内阴暗，灌丛 和草本种类少，仅分布有刺通草( Trevesia palmata)、 五叶悬钩子 (Rubus quinquefoliolatus)、锦鸡儿( Galagana sp. )、鳞毛蕨( Dryopteris sp. )、五叶草( Geranium nepalense $)$ 等。冬季在大脑子、8 月份在南斋公房 均见白尾梢虹雉于该生境中活动。

\section{3 讨论}

\section{1 濒危原因分析}

目前有关白尾梢虹雉的国际贸易极少，印度部 分地区用其羽毛制作装饰品而导致种群数量下降 (Fuller \& Garson 2000) ,而在中国末见白尾梢虹雉 贸易，商业用途不是白尾梢虹雉的致危因素。云南 建立高黎贡山自然保护区对保护白尾梢虹雉及其栖 息地起到了积极作用，但因高黎贡山和怒山山脉地 形陡峭, 高山与村镇相距遥远, 控制偷猎难度大, 所 以即使在保护区内，白尾梢虹雉的生存状况也不容 乐观。归纳该物种的濒危原因有以下几点。

\subsection{1 栖息生境承载量小}

白尾梢虹雉在长期的进化过程中，已经适应了 温度低、湿度大、云雾多的高山环境，仅分布在高海 拔的箭竹林、针叶林和草甸等生境中，而这几种生境 类型局限于高山, 面积相对狭小,生产力水平低, 动 物承载量小, 这是决定白尾梢虹雉分布局限和数量 稀少的最主要因素。

\subsection{2 种群增长慢}

作者于 $2002-2003$ 年的春季在高黎贡山大塘 做白尾梢虹雉生态观察时，观察到 1 雄 2 雌的家族 内仅有 1 只雌鸟繁殖, 窝卵数 $2-3$ 枚, 孵化期长达 $28 \mathrm{~d}$ 。窝卵数少、孵化期长、繁殖雌体比例小限制了 其种群的增长, 与何芬奇 (1991) 观察结果类似。

\subsection{3 人类活动干扰}

上山挖野菜、找兰花是当地群众的习惯, 这种行 为严重破坏了地表植被，对白尾梢虹雉的栖息生境 和食物都有一定影响。2002 年 6 月 5 日至 21 日， 我们在大脑子附近做研究, 短短 $17 \mathrm{~d}$ 内当地群众共 77 人次上至主山脊挖野菜,声音嘈杂, 多次将白尾 梢虹雉惊飞。另外, 翻越高黎贡山的古道较多，如南 斋公房、北斋公房、片马垭口等, 当地群众过往频繁。 例如 2000 年 8 月以及 2001 年3-4 月，作者在高黎 贡山南斋公房附近做研究, 每天从古道上过路的群 众达 3-4 人次/ $\mathrm{d}$ 。虽然没有直接对动物造成伤害， 但有可能影响动物种群的扩散, 并诱发偷猎, 是该物 种的潜在致危因素。

\section{1 .4 宣传不力}

宣传不力是白尾梢虹雉等众多濒危物种得不到 有效保护的原因。笔者调查期间曾对 200 多位村民 作过访问, $90 \%$ 以上的村民不知道白尾梢虹雉是国 
家 I 级保护动物, 特别是当访问对象为妇女、15 岁 以下的少年儿童和 50 岁以上的老人时, 很少有人知 道鸟类中还有受法律保护不准猎捕的种类。

\section{2 保护对策}

如何保护白尾梢虹雉, 使其在自然界的种群数 量不再下降, 以及如何恢复种群是当前急待解决的 问题。建议采取以下措施。

\subsection{1 开展驯养繁殖}

目前尚未建立白尾梢虹雉人工饲养种群, 1998 年云南省野生动物收容救护中心从野外引种 1 对， 1997 年北京大兴濒危动物驯养繁殖中心从云南滇 西北野外引入 4 对亚成鸟, 进行驯养繁殖。云南的 1 对鸟未繁殖成功 北京大兴的引入鸟于 1999 年开 始产卵繁殖, 目前仅存 4 只雌鸟, 其中 2 只为人工饲 养繁殖的子代鸟。这些工作表明白尾梢虹雉在人工 饲养条件下能存活并繁殖，但成效不理想。除与养 殖单位的人力财力投入和技术力量相关 ,也与人们 对该物种生态习性了解太少有关。鉴于人工繁育是 迁地保护的重要措施, 白尾梢虹雉又具有很高的观 常价值，人工饲养繁殖还应继续探索，若取得成功， 可为该种迁地保护奠定基础。

\section{2 .2 加强禁止偷猎的法制宣传}

白尾梢虹雉繁殖力低, 种群数量增长缓慢 猎捕 很容易造成其数量骤然下降。在其繁殖季节应限制 人员出入有白尾梢虹雉分布的高山区域,减少人为 干扰, 避免偷猎。另外应加强宣传教育, 使当地村民 了解白尾梢虹雉的法律保护地位, 并引导他们加入 到保护该鸟的行列中来。

\subsection{3 加强基础研究}

白尾梢虹雉分布局限于喜马拉雅山脉东部和横 断山地区中部,栖息地均位于高山,给研究带来困 难，人们对该物种的认识和了解十分有限，还需要加 大基础研究。继续进行分布地点调查和详尽的生态 生物学研究, 特别需要关注该种的种群结构及波动、
繁殖生物学和栖息地选择等问题。

致谢: 承蒙中科院动物研究所何芬奇研究员、中科 院昆明动物研究所杨晓君研究员提供标本采集地信 息及观察资料, 北京师范大学生命科学学院张正旺 博士提供大兴濒危动物驯养繁殖中心的繁殖信息， 西南林学院植物学教研室硕士研究生王玉兵和许先 鹏帮助鉴定植物标本, 中科院昆明动物研究所梁琳 协助制作分布图，特此致谢！

\section{参考文献}

Bird Group, Kunming Institute of Zoology, Chinese Academy of Sciences (中国科学院昆明动物所鸟类组). 1980. Survey Report of Vertebrates in Gaoligongshan Region, Vol. 2, Birds (高黎贡山地区脊椎动物考察报告, 第二册, 乌 类). Science Press, Beijing, 30-31. (in Chinese)

Fuller, R. A. and Garson, P. J. 2000. Pheasants: Status Survey and Conservation Action Plan 2000 - 2004. Information Press, Oxford, $28-29$.

He, F. Q. (何芬奇). 1991. Lophophorus sclateri. In: Lu, T. C. (卢汰春) ( ed.), Chinese Rare and Endangered Wild Pheasants (中国珍稀濒危野生鸡类). Fujian Science and Technology Press, Fuzhou, 211 -214. ( in Chinese)

Shi, X. C. (施晓春) . 1999. Preliminary observation on Lophophorus sclateri in Mountain Gaoligongshan. Zoological Research (动物学研究), 20: 50 - 54. (in Chinese with English abstract)

Tang, C. Z. (唐蟾珠). 1996. Birds of the Hengduan Mountains Region (横断山区乌类). Science Press, Beijing, 113 - 114. (in Chinese)

Yang, X. J. (杨晓君). 1995. Lophophorus sclateri. In: Yang, L. (杨岗) ( ed.), The Avifauna of Yunnan, China(云南鸟 类志, 上卷, 非雀形目). Yunnan Science and Technology Press, Kunming, 278-280. (in Chinese)

Zheng, Z. X. (郑作新). 1978. Fauna Sinica, Aves. Vol. 4: Galliformes (中国动物志 $\square$ 乌纲 $\square$ 鸡形目). Science Press, Beijing, $124-126$. (in Chinese) 